\title{
Cartas provincianas: Gilberto Freyre e Manuel Bandeira em crônica epistolar
}

\section{Silvana Moreli Vicente}

Resumo Gilberto Freyre e Manuel Bandeira começaram a trocar cartas em 1925. A leitura do conjunto lança luz sobre o estilo de escrita de ambos, além de ajudar a compor um quadro com elementos fundamentais para se compreender a dinâmica do Modernismo no Brasil. Recife e Rio de Janeiro são os espaços em que desfilam personagens e episódios contados nas linhas dessas "crônicas 'epistolares". Palavras-chave Gilberto Freyre; Manuel Bandeira; cartas no Modernismo brasileiro.

Abstract Gilberto Freyre and Manuel Bandeira started to exchange letters in 1925. The reading of this material highlights the literary style of both writers, as well as helps to build a cultural background that is fundamental to comprehend the dynamics of the Modernism in Brazil. Recıfe and São Paulo are the locations of some characters and episodes of these "epistolary chronics". Keywords Gilberto Freyre; Manuel Bandeira; letters in the Brazilian Modernism. 
A epistolografia em Gilberto Freyre entra como prática paraliterária que se afirma com especial relevo dentro de uma obra que procurou dignificar formas consideradas secundárias, impuras ou fronteiriças, como o ensaio, a autobiografia, a biografia, as memórias, o diário etc. Muito cedo Freyre foi um escritor de cartas. Sua correspondência - em grande parte ainda inédita - consegue deixar a marca de um tempo, de uma história pessoal e coletiva centrada no Recife; espraia-se pelos quatro cantos do país, pela América Latina, Estados Unidos, Europa, África etc. Assumindo a postura de um humanista que por tudo se interessa, que tem pavor do pensamento sectário e do saber especializado, Freyre também consegue compor uma lista de correspondentes da qual fazem parte as figuras mais controversas do século $\mathrm{xx}$ e que vai do grupo de escritores modernistas avant-garde a colaboradores de Portugal salazarista e neocolonialista.

Particularmente as cartas trocadas entre Gilberto Freyre e Manuel Bandeira estão entre aquelas que configuram um mundo à parte, de relações que se desenrolam em tom menor, sem pretensão de grandeza. Nelas, o miúdo da vida cotidiana é desfiado de um para o outro: de um lado, o recifense radicado no Rio de Janeiro Manuel Bandeira tem a oportunidade de travar relações mais próximas com sua terra, de se provincianizar; de outro, o recifense cosmopolita Gilberto Freyre pode atualizar-se e viver, quando não presencialmente, os burburinhos das rodas intelectuais e literárias do então Distrito Federal. As cartas, desse modo, testemunham que não havia propriamente um abismo entre o Modernismo do eixo Rio-São Paulo e o Modernismo do Nordeste. Diferenças por certo existiram, alimentadas por rixas individuais, mas, sobretudo nas décadas de 1920 e 30, as confluências foram várias e os documentos da época confirmam a colaboração mútua.'

1 Nesse contexto, vale recuperar o contraponto realizado por Gilda de Mello e Souza: "Em resumo: as diferenças notórias que, no decorrer dos anos, afastam Gilber to Freyre de Mário de Andrade nāo impediam a espécie de cruzamento que no decênio de 1920 os aproxima, quando o primeiro, depois da estadia nos Estados Unidos, volta para o Brasil e o segundo encerra com Macunaíma a etapa nacionalista que havia construído no gabinete. É o momento em que ambos pensam o Brasil moderno sem perder o contacto com a cultura popular e a contribuiçāo do passado, embora cada um realize essa tarefa [...] segundo seu temperamento e anseio cultural" (SOUZA, Gilda de Mello e. O mestre de Apipucos e o turista aprendiz. In: A ideia e o figurado. São Paulo: Duas Cidades/ Editora 34, 2005). Importa ainda dizer que, nas duas direções, a presença amiga e constante de Manuel Bandeira foi decisiva: de um lado, dialogando com o projeto nacio-

190 • VICENTE, Silvana Moreli. Cartas provincianas: Gilberto Freyre e Manuel Bandeira... 
Quando Freyre e Bandeira iniciam a correspondência, este já era um escritor respeitado nos círculos modernistas do Rio e São Paulo. A relação que se estabelece é de grande consideração de ambas as partes. Quatorze anos mais velho, Bandeira também inspira confiança como homem experimentado, que não seria alvo fácil da fúria de um jovem e quixotesco aspirante a escritor. Desse modo, esta é uma das poucas relações que se resguardam da incontrolada ânsia devoradora daquele que se tornaria "o mestre de Apipucos". Diante do escritor sóbrio e discreto que é Bandeira, Freyre tem a oportunidade de exercitar uma escrita mais simples, sem os grandes torneios sintáticos que caracterizam seu estilo de linhas barrocas. É como se o ideal franciscano de vida e escrita, manifestado em alguns de seus textos - franciscanismo "inimigo do intelectualismo; inimigo do mercantilismo; lírico na sua simplicidade; amigo das artes manuais e das pequenas indústrias; e quase animista e totemista na sua relação com a Natureza, com a vida animal e vegetal", ${ }^{2}$ portanto uma espécie de categoria simbólica característica do mundo orgânico pré-burguês -, aqui pudesse ser mais livremente experimentado, sem pompas, sem grandes lances. Em verdade, o lirismo em tom menor acaba dando a tônica de muitas dessas cartas, como esta de Bandeira, datada de 1935:

Afinal desencantei a viagem a Cambuquira. Estou aqui desde o dia 15, e parece que as águas estão me fazendo grande bem.

Gostei muito de Cambuquira, que é bem simples e bonitinha. O que estraga um pouco isto são os aquáticos - gente que tem quase todos um ar pará de favorecidos da sorte, muito irritante. Tenho levado uma vida de completo repouso, levantando às 6 da manhã e deitando às 9 da noite.

Anteontem fui numa excursão a Campanha, cidadezinha morta que fica a um $3 / 4$ de hora daqui. Faz agora justamente 30 anos que cheguei lá carregado. Verifiquei que era um camelo em 1905, pois não senti então a delícia que são aquelas ruas tão simples, tão modestas, com os seus casarões quadrados, quase todas com bicos de telhado em forma de asa de pombo. Há lá uma rua Direita (hoje tem nome de gente) que é

nalista de Mário de Andrade; de outro, dando alento à ideia de província e de região que então Gilberto Freyre procurava desenvolver.

2 FREYRE, Gilberto. Casa-grande \& senzala. Rio de Janeiro: Record, 2000, p. 212. 
um encanto: tão genuinamente brasileira, tão boa, dando vontade de morar nela. $\mathrm{O}$ passeio que foi de noite, com o luar (uma lua sem nada de mozarlesco, lua-Dantas, simples e bom satélite) foi dessas cousas que a gente não esquece. Diante das duas casas onde morávamos, e onde passei o Diabo, me senti valado, com um nó na garganta. Assim como no interior da matriz, uma igreja tristíssima, [fase] essa, sim, parece o "huge baru" que Luccock viu nas igrejas de Ouro Preto. Faziam a Via-Sacra e eu estive longo tempo imaginando quantas vezes minha mãe e minha irmã estiveram ali ajoelhadas rezando para que eu não morresse. ${ }^{3}$

Esse trecho é de um lirismo tocante pela discrição e sobriedade de expressão. $O$ modo de descrever o estilo de vida pacato da pequena cidade é como uma pintura de paisagem de linhas rápidas que registrasse um instante particularíssimo. A despeito da despretensão com que é realizada, esta composição com palavras corridas e impressōes ligeiras toma uma dimensão confessional que procura destacar da vida que passa algo de imortal, de verdade sempiterna. Esta beleza é antevista por meio do contato epistolar enquanto ato desprendido de diálogo entre amigos. Notese como a sensibilidade do poeta procura compor um quadro singelo, em que a bondade, como qualidade, é um misto de psicologia do indivíduo, da coletividade e dos espaços que "têm alma", com suas "ruas tão simples, tão modestas", "uma rua Direita [...] que é um encanto: tão genuinamente brasileira, tão boa, dando vontade de morar nela". O estilo de escrita é de uma simplicidade tocante: os adjetivos são poucos, quase minimalistas e pueris ("simples", "bonitinha", "modesta", "boa", "tristíssima"), e a sintaxe é essencialmente paratática, sem grandes torneios.

Numa pequena mudança de tom, mas que não compromete a essência do todo, o remetente, até agora uma construção autoral que se passaria como um ingênuo de primeira natureza, reflete, no período seguinte, sobre seu próprio destino e, nessa autoironia de toques românticos, confidencia o teor dessa amizade de uma década, fundamentalmente construída por cartas e por noites de boêmia nas ruas cariocas:

3 Carta de Manuel Bandeira a Gilberto Freyre. Cambuquira, 23 de março de 1935 (Centro de Documentação da Fundação Gilberto Freyre, Recife). @ das cartas e demais textos de Manuel Bandeira, do Condomínio dos Proprietários dos Direitos Intelectuais de Manuel Bandeira. Direitos cedidos por Solombra - Agência Literária (solombra@solombra.org).

192 - VICENTE, Silvana Moreli. Cartas provincianas: Gilberto Freyre e Manuel Bandeira... 
Esta vida é uma merda, seu Gilberto. Mas não quero acabar com amarguras esta carta. No descalabro que foi a minha vida, ainda me sobram amizades sólidas como a das Blanks, a sua, do Rodrigo e poucos mais. E quis escrever isto a você para dizer que a lembrança destes bons amigos me acompanhava enquanto eu andava como um fantasma sem eira nem beira pelas ruas desertas daquela cidadezinha morta. ${ }^{4}$

O modo como Bandeira se expressa ao amigo parece encontrar perfeita correlação na forma do relato simples: trata-se de uma correspondência íntima, que se quer sincera e desprendida de maiores intenções, de base essencialmente afetiva. A correspondência como gênero textual, por explorar esta esfera da intimidade, por não desejar cultivar um público amplo e não querer uma tensa urdidura ou arte stricto sensu, destaca-se de outros gêneros textuais amplamente cultivados, como o romance, a poesia e o drama; porém, é interessante notar que a maneira como ela se realiza tem muito a ver com a construção lírica de Bandeira, pela aproximação íntima e afetiva com a realidade, com o cotidiano, com a vida comum. $O$ desprendimento que vemos também nas crônicas liga-se indiretamente com a correspondência enquanto prática textual. Num mundo em que os indivíduos progressivamente se afastam, compelidos pela sociedade de massa a uma anulação do eu, como contraste aqui haveria uma vivência afetiva intensamente humana, vital.

Também essa troca, cuja tônica é dada por Bandeira, nada tem da retórica socialmente estabelecida para o relacionamento entre indivíduos dominante até o século XIX, desenvolvida essencialmente no seio da sociedade estratificada e hierarquizada segundo códigos de convivência dos tempos coloniais e monárquicos. $\mathrm{O}$ alto grau de formalização foi justamente bombardeado com o fortalecimento da sociedade burguesa e com os discursos que fomentavam os anseios de democratização da educação e da cultura, o que no Brasil se deu mais uniformemente a partir do século xx. Como contraste a essa escrita bela e desprendida de Bandeira, temos, a seguir, um pequeno exemplo de domínio do código socialmente elaborado que regia a correspondência entre Gilberto Freyre e Oliveira Lima, alto representante da elite culta e esclarecida no Brasil do século XIX. Freyre escreve em 1923:

4 Idem. 
Recebi sua amável cartinha e as três cartas de apresentação para São Paulo. Não sei como agradecer tanta gentileza da sua parte. Já não são poucos os incômodos que lhe tenho causado. Sabe que, por motivos de educação um tanto hirta que recebi e talvez por isso mesmo - mas não estou certo - de temperamento, não sou efusivo nem quando escrevo nem quando falo. Creio mesmo que o outro extremo, o que lamento. Porém creia, meu caro amigo, que o amo com todo coração - ao Senhor è à Dona Flora, alma irmã da sua, nobre e boa. Isto pondo à parte os obséquios recebidos. Simples obséquios não criam uma grande estima; não o faz a mera gratidão. Dizia Emerson que os favores eram como maçãs que se davam a crianças e logo esquecidas. $O$ que uma pessoa de bem não esquece é a inspiração recebida d'outra - e sua vida e a sua alma e a sua amizade quase paternal têm sido para mim forte inspiração. Como esta carta é muito íntima não hesito em revelar que o seu nome e o de Dona Flora estão não só na minha lembrança como nas minhas preces. ${ }^{5}$

Gilberto Freyre lança mão, neste momento, de um expediente estilístico recorrente em sua escrita. Afirma uma simplicidade retórica negada na própria forma de expressāo, ou seja, paradoxalmente diz aquilo que não faz, ou aplica o seu contrário. $\mathrm{O}$ autor afirma que nāo conseguiria desenvolver aquela adequação rara entre forma e conteúdo pelo simples fato de que agradecer ao destinatário implicaria uma forma grandiloquente pela própria natureza grandiosa dos gestos que lhe foram dedicados. Constatação propalada pelo autor: ele não é efusivo, ou seja, não se dá ao derramamento sentimental, nem quando escreve, nem quando fala. Tratar-se-ia de uma escrita "magra", consequência de "educação um tanto hirta" ou temperamento. Contudo, a escrita com seus rodeios e imagens surpreendentes mostra o contrário: "o amo com todo coração - ao Senhor e à Dona Flora, alma irmã da sua, nobre e boa". O que vemos, desse modo, é a aplicação de um expediente retórico de linhas barrocas com o maior de seus brilhos numa comunicação do dia a dia. Freyre sabia compor arabescos literários como ninguém e deles se serviu, em inúmeros momentos, para aglutinar imagens as mais contrastantes,

5 Carta de Freyre a Oliveira Lima. Lisboa, Consulado do Brasil, 05/02/1923. In: FREYRE, Gilberto. Em familia: a correspondência de Oliveira Lima a Gilberto Freyre. GOMES, Ângela de Castro (Org.). Campinas: Mercado de Letras, 2005, p. 166-7.

194 - VICENTE, Silvana Moreli. Cartas provincianas: Gilberto Freyre e Manuel Bandeira... 
posições as mais inconciliáveis, sensações as mais chocantes, numa escrita que certamente bebeu muito da retórica dos Seiscentos e que tem bastante a ver com a sua abordagem da herança do Brasil patriarcal, em sua plasticidade e sincretismo. Se o Brasil, na perspectiva do sociólogo, encontrou caminhos para combinar seus contrários, inicialmente pelo intercurso sexual, igualmente sua escrita foi sendo lapidada no sentido de desenvolver formas de assimilação agregadora. $\mathrm{Ou}$, ainda, um modo privilegiado de abrigar o contrário daquilo que se diz pode ser visto sem dúvida no polêmico tema da pressuposta visão idílica da escravidão no Brasil, afirmada mas retoricamente negada ao longo das páginas de Casa-grande \& senzala, que se esmeram no sentido de dar vida a quadros narrativos dos mais cruéis e dramáticos. Assim como o discurso de Freyre, em seus melhores ensaios, se configura com idas e vindas, afirmações e negações, avanços e retrocessos que tipificam o universo impuro de contradições próprias da nova civilização, sua correspondência encarna inúmeros paradoxos. A documentação epistolar, apesar de ser um conjunto aparentemente secundário, mostra também o quanto a figuração retórica estava impregnada em seu discurso mais íntimo.

Por outro lado, ainda sobre a expansiva reverência a Oliveira Lima, a resposta deste àquelas palavras de fato efusivas foi, digamos, magra, mas expressa uma espécie de autêntico amor paternal, de doação para a qual não se espera nenhuma recompensa:

Recebi a sua última de 5 de fevereiro. Não me agradeça: não há motivo para isso. $\mathrm{O}$ sr. é bastante efusivo pelos seus atos, não precisa sê-lo pelas suas palavras. Os atos valem mais. Nós o estimamos muito e desejamos de coração vê-lo feliz. Penso que se o sr. for para São Paulo, dar-se-á bem. ${ }^{6}$

Freyre parece alimentar-se, de forma mais flagrante que Bandeira, de paradoxos. Porém, aquilo que o sociólogo chama de harmonia de antagonismos, porquanto considera metades que não se misturam, fica bem evidente na própria maneira como ele se autorretrata, falando de incompatibilidades, de privações, de

6 Carta de Oliveira Lima a Gilberto Freyre. Frankfurt, 17/02/1923. In: FREYRE, Gilberto. Op. cit., p. 168. 
antagonismos - "a vida de scholar gipsy priva o homem da vida simples"7 Talvez a figura de linguagem mais adequada para dizer esta harmonização de antagonismos seja a antítese, já que temos uma combinação, como em mosaico, de duas metades conflitantes, que só podem ser destrinchadas no detalhe pelo analista atento:

E um desses dias, aí chegará num cargueiro ou na 3a classe [...] este provinciano (cosmopolita, cigano, romântico, modern. ${ }^{8}$ intellectual, radical, reacionário, revolucionário, ortodoxo, Raul dos Passos - irmão do Dos Passos. daqui, o de Three soldiers. [Seraphim] Jung, Iorge Rialto, Antonio Ricardo ${ }^{9}$ etc. etc. - oxoniano, M. A. ${ }^{10}$ Columbia, Stanfordiano, etc. etc. etc.). Raspado tudo isso, o provinciano, a quem todas as festas da Califórnia não fazem esquecer o gosto amargo (desculpe esse classicismozinho) de um maracatu do Outeiro [...]. Entretanto, eu posso raspar tudo isso de mim? Não [...], a nostalgia do grande mundo não me deixará de todo; as memórias que estavam secando, abriram-se de novo [...]. Meu caro Flag, desculpe tanta literatura; não é só literatura."

O que atrai o leitor não é só o exercício daquela "ambiguidade dinâmica", expressão cunhada por Antonio Candido ${ }^{12}$, mas um exemplo de astúcia autoral que caracteriza seus, a meu ver, mais brilhantes ensaios literários à la Montaigne. Esta

7 Carta de Gilberto Freyre a Manuel Bandeira. 9 de janeiro de 1931 (Arquivo-Museu de Literatura Brasileira da Fundaçāo Casa de Rui Barbosa, Rio de Janeiro).

8 Os sublinhados são do original.

9 Jorge Rialto e Antônio Ricardo são alguns dos pseudônimos que Gilberto Freyre utilizou em artigos para A Província, periódico do Recife.

10 Abreviação do título de Magister Artium ou Master of Arts, que Gilberto Freyre recebeu na Universidade de Columbia apresentando a dissertação Social Life in Brazil in the Middle of the 19th Century, defendida em 1922.

11 Carta de Gilberto Freyre a Manuel Bandeira. 9 de janeiro de 1931 (Arquivo-Museu de Literatura Brasileira da Fundação Casa de Rui Barbosa, Rio de Janeiro).

12 Segundo Antonio Candido, "uma vez constatado que é difícil e desnecessário classificá-lo, dada a natureza da sua personalidade intelectual, a fecunda diversidade do seu pluralismo, compreendemos melhor a ambiguidade dinâmica sentida na leitura da sua obra, - onde, quando saímos à busca do sociólogo, deslizamos para o escritor; e quando procuramos o escritor, damos com o sociólogo. Se procuramos especificamente o crítico, acharemos quase sempre o estudioso que utiliza impuramente a literatura para fins da sua construção sociológica; mas a impura utilização torna-se de súbito tratamento vivificante, que retorna sobre a literatura a fim de esclarecê-la". (CANDIDO, Antonio. Gilberto Freyre: crítico literário. In: AMADO, Gilberto et alii. Gilberto Freyre - sua ciência, sua filosofia, sua arte. Rio de Janeiro: José Olympio, 1962, p. 120-1.)

196 - VICENTE, Silvana Moreli. Cartas provincianas: Gilberto Freyre e Manuel Bandeira... 
dramatização da persona lança luz sobre um jogo intenso de máscaras que se chocam e se combinam a todo momento. Tal vontade de expressão que permeia os momentos mais tranquilos da vida podemos observar neste trecho, em que Gilberto Freyre, em 28 de dezembro de 1934, fala sobre si em terceira pessoa:

Bons anos! A v. e às boas amigas Blank, inclusive a pequenininha - Bons Anos! Estou com saudades. V. não dá um ar de sua graça, deixa o provinciano [sem] notícias, fora das novidades da Metrópole. Mas o provinciano não esquece v. nem as boas amigas de Santa Teresa. O provinciano atravessou um ano que não foi dos melhores de sua vida - doente quase todos estes últimos seis meses. [Finalmente] parece que voltou agora do seu "equilíbrio [fisiológico]" O provinciano está feliz no casarão velho onde mora agora com a família, numa puxada assobradada - puxado, dizem os requintados de Capiberibe, mas nós provincianos das margens do [Capibaribe] dizemos puxada. (Coisa velha e boa, bem boa, mas não deixo [de] ter saudades do K. ${ }^{13}$ onde esperava viver toda a vida.) O provinciano está sentimental. O provinciano tem estado horrivelmente sentimental, até mesmo atacado de "self-pity" Já esteve uma vez assim e curou-se lendo Nietzsche. Agora, com tanto [...], não tem recorrido a Nietzsche: tem recorrido ao fumo. [...] Mas cigarro só inglês, que o provinciano tem coisas de requintado misturadas com o seu plebeísmo de club [...] e festas de igreja. Vou deixar essa história de "o provinciano" que está virando literatura e retomar o meu eu. ${ }^{14}$

É bastante difícil separar o que é exercício de estilo do que é expressão sincera. De qualquer modo, toda ela é tomada por aquela ambiguidade dinâmica que vaza o discurso aparentemente simples. O que temos é uma vontade quase doentia de contar e recontar a própria história e de usar tintas em combinação intensamente dramática.

No ensaio "A literatura moderna do Brasil", Freyre, ao final, dedica considerações acerca da centralidade do Recife - a capital intelectual do Nordeste, segundo o

13 "K." provavelmente significa Carrapicho (Karrapicho), casa mourisca que pertencia a Ulysses Freyre, irmāo de Gilberto. Foi ali que Gilberto Freyre escreveu Casa-grande \& senzala

14 Carta de Gilberto Freyre a Manuel Bandeira. Recife, 28 de dezembro de 1934 (Arquivo-Museu de Literatura Brasileira da Fundaçāo Casa de Rui Barbosa, Rio de Janeiro). 
escritor - para a revolução que se teria processado no Brasil da primeira metade do século $\mathrm{xx}$. As palavras que utiliza para tanto são fundamentalmente centrípetas, ou melhor, lançam foco sobre as coisas de dentro, sobre a intimidade, sobre a província:

Resistindo à ideia de que o progresso material e técnico deve ser tomado como a medida da grandeza do Brasil, os regionalistas brasileiros viam no amor à província, à região, ao município, à cidade ou à aldeia nativa condição básica para obras honestas, autênticas, genuinamente criadoras e não um fim em si estreito. ${ }^{15}$

Ao valorizar demasiadamente o papel da província nos processos culturais, o Gilberto Freyre mais cético, combativo e polêmico perde um pouco sua força quando não lança mão daqueles expedientes formais de choque. Ser um provinciano virtuoso é contrapor-se também aos valores cosmopolitas enxertados num país de características únicas, mas não desprezá-los de todo. Por isso existe o mau e o bom provinciano, sendo que este jamais deve deixar de empregar um estilo vivaz e espirituoso, sob pena de se perder numa exaltação vazia e baixa, excessivamente sentimental, das coisas da terra. Vale dizer que, ao dizer-se provinciano, Freyre também finca os pés num discurso bastante policiado, sujeito às críticas mais severas, aos preconceitos mais desonestos. Grande parte dessa linha de força contrária aos valores da província enraíza-se na própria ideia de modernidade que se propaga ao longo dos séculos XIX e Xx, como nota o crítico italiano Alfonso Berardinelli:

A modernidade, especialmente a modernidade poética, nasceu como negação da província, daquele universo orgânico, internamente estruturado, intensamente visível em cada uma de suas partes e fechado que é a província. Fechamento de onde se entrevê ou se sonha um espaço livre e aberto. Província é antes de tudo o limite, a fronteira além da qual deveria existir ou se imagina que exista o Grande Mundo. ${ }^{16}$

15 FREYRE, Gilberto. "A literatura moderna no Brasil". In: A interpretaçāo do Brasil. São Paulo: Companhia das Letras, 2001, p. 313

16 BERARDINELLI, Alfonso. "Cosmopolitismo e provincianismo na poesia moderna". In: Da poesia à prosa. Trad. de Maurício Santana Dias. Org. e prefácio Maria Betânia Amoroso. Sāo Paulo: Cosac Naify, 2007 , p. 68.

198 • VICENTE, Silvana Moreli. Cartas provincianas: Gilberto Freyre e Manuel Bandeira... 
Negar uma literatura intransitiva, essencialmente metalinguística e fragmentada, carro-chefe da proposta moderna, a fim de privilegiar a comunicação, o sentido de completude e fechamento de origem arcaica, bombardeados pelos mesmos discursos da modernidade avant-garde, é ainda mais temerário num país que é também marginal, província, tendo em vista a conjuntura geopolítica que o submete aos centros metropolitanos do capitalismo avançado. Porém, Freyre lança mão das duas moedas: daquela mais provinciana e tradicional combinada àquela mais vanguardista e moderna. A boa mistura dá "o provinciano do bom". Assim, aquela instância autoral intensamente buscada que, sendo o bom provinciano, incomoda, agita, duvida, brinca, desconcerta - e que já tirou do sério mesmo o próprio Bandeira, conhecido por sua tolerância e parcimônia ("As nossas cartas se cruzaram. Não há, pois, motivo para as lamuriazinhas irônicas do sociólogo"17) -, mostra-se com toda a sua verve em alguns documentos epistolares. Assim, se por um lado Bandeira é indiscutivelmente dono de uma escrita límpida e aparentemente simples, nos moldes idealizados pela tradição modernista, Freyre, de outro modo, deixa claros exemplos de uma tentativa de penetrar o universo ficcional, da criação literária propriamente dita. ${ }^{18}$ Poder-se-ia dizer que as cartas deste, em alguma medida, sāo impuras e, por isso, mais problemáticas, apesar de trazerem como dominante o fait divers. Em crônica de Bandeira que toma como assunto uma brincadeira de Jaime Ovalle e Augusto Frederico Schmidt, Freyre é

17 Carta de Manuel Bandeira a Gilberto Freyre. Rio de Janeiro, 10 de janeiro de 1934 (Centro de Documentação da Fundação Gilberto Freyre, Recife).

18 Em alguns momentos, Freyre revela-se um nada ingênuo escritor de cartas. Particularmente nos anos que antecedem a combustão do Modernismo brasileiro, procurando desenvolver uma linguagem voltada para a comunicação da experiência, para a vida cotidiana, mostra saber dominar e explorar os códigos da escrita epistolar na elaboração de artigos para o jornal Diário de Pernambuco. Naquele rol de formas impuras, todos são um misto de crônica, diário de viagem, ensaio, autorretrato e carta. Esses textos foram enviados periodicamente quando o escritor morava nos Estados Unidos (1918-1923) para a seção do jornal intitulada "Da outra América" (In: FREYRE, Gilberto. Tempo de aprendiz. São Paulo: Ibrasa, 1979). Também importa dizer que uma das personagens que funcionam como modelo para o escritor é Fradique Mendes, ficcionalizado por Eça de Queirós por meio de cartas de sabor ácido e polêmico enviadas a inúmeros destinatários em Portugal no final do século XIX. Fradique, personagem cosmopolita de tendência conservadora, dono de um estilo mordaz - que antecipa, e muito, o próprio estilo freyriano -, é chamado à baila em inúmeros trabalhos publicados pelo sociólogo, até mesmo em sua correspondência. 
retratado de modo acertado. Seu sense of humour só pode ser objetivamente entendido dentro da tradição dos grandes polemistas de língua inglesa:

Restam os Onésimos... O Onésimo onde aparece é assim: duvida, sorri, desaponta; diante dele ninguém tem coragem de chorar. O seu sense of humour sempre vigilante é o terror dos Mozarlescos avisados. Não é que o faça por maldade: os Onésimos não são maus. O drama íntimo dos Onésimos é não se sentirem entusiasmados por nada, não encontrarem nunca uma finalidade na vida. Não obstante, se as circunstâncias os colocam inesperadamente num posto de responsabilidade, podem atuar (não todos, é verdade) com o mais inflexível senso do dever. O sr. Gilberto Freyre, por exemplo, é Onésimo. Em geral os humoristas são Onésimos. Não os humoristas nacionais, que esses pertencem todos ao exército do Pará (os srs. Mendes Fradique, Raul Pederneiras, Luís Peixoto, etc. Aporelli faz exceção, é Dantas.) Mas os grandes humoristas, Sterne, Swift, Heine são Onésimos. O sr. João Ribeiro é um exemplo muito curioso de Onésimo. O escritor paulista Couto de Barros, outro. ${ }^{19}$

O sentido da forma impura e da ambiguidade dinâmica encontra sua contrapartida quando o autor consegue desenvolver uma visão de Brasil original, definida a partir da identidade mestiça. Assim, trata-se também de um dinamismo de persona único, que bem justifica a interpretação de ensaios como Casa-grande \& senzala como um ensaio autobiográfico. ${ }^{20}$

19 BANDEIRA, Manuel. A nova gnomonia. In: Crônicas da Provincia do Brasil. São Paulo: Cosac Naify, 2006, p. 160. Elvia Bezerra esclarece no livro A Trinca do Curvelo: "Um outro legado de Jaime Ovalle, em parceria com Augusto Frederico Schmidt, foi a criação de um curioso sistema de classificação dos homens, explicada com detalhes na crônica de Manuel Bandeira 'A nova gnomonia'. Em síntese, sāo cinco os tipos, cada um com seu anjo inspirador: os Parás, os Dantas, os Mozarlescos, os Kernianos e os Onésimos. / Os Parás são os extrovertidos, ágeis, que vencem quando chegados do Norte. Visam o sucesso. Os Dantas teriam em Cristo o representante perfeito: são desprendidos, puros, amantes da verdade. Os Mozarlescos sāo sentimentais e têm em Cícero Dias, com as suas luas em lágrimas e estrelas sorridentes, um exemplo de categoria. Ribeiro Couto seria um Kerniano típico: arrebatado, impulsivo. E por fim os Onésimos, que são céticos, desapontam. Machado de Assis seria um Onésimo. O conhecimento dessa classificação era imprescindivel a quem se aproximasse do grupo". (BEZERRA, Elvia. A Trinca do Curvelo: Manuel Bandeira, Ribeiro Couto e Nise da Silveira. Rio de Janeiro: Topbooks, 1995, p. 85.)

20 Para Roberto Ventura, "Casa-grande \& senzala se converte em autobiografia sexual, em que o notável apetite priápico de seu autor ganha dimensōes histórico-sociais" (VENTURA, Roberto. Casa-grande \& senzala. São Paulo: Publifolha, 2000, p. 57).

200 - VICENTE, Silvana Moreli. Cartas provincianas: Gilberto Freyre e Manuel Bandeira... 
Inclusive, o modo antitético como elabora seu discurso parece tocar particularmente uma geração de escritores, dentre eles o próprio Manuel Bandeira. Ser provinciano implica algo muito além da elaboração do autorretrato; passa a ser uma categoria ético-estilística, um modo particular de estar no mundo e de concepção artística, uma espécie de estetização empenhada da persona, já que procura aumentar a densidade comunicativa da expressão pessoal, na contramão do esvaziamento apontado por teóricos da literatura moderna como Hugo Friedrich em sua Estrutura da lírica moderna. ${ }^{21}$ É assim que Bandeira se assume um escritor provinciano:

Sou provinciano. Com os provincianos me sinto bem. Se com estas palavras ofendo algum mineiro requintado peço desculpas. Me explico: as palavras "província", "provinciano", "provincianismo" são geralmente empregadas pejorativamente por só se enxergar nelas as limitações do meio pequeno. Há, é certo, um provincianismo detestável. Justamente o que namora a "Corte". O jornaleco de município que adota feição material dos vespertinos vibrantes e nervosos do Rio - eis um exemplo de provincianismo bocó. É provinciano, mas provinciano do bom, aquele que está nos hábitos do seu meio, que sente as realidades, as necessidades do seu meio. Esse sente as excelências da província. Não tem vergonha da província - tem é orgulho. Conheço um sujeito de Pernambuco, cujo nome não escrevo porque é tabu e cultiva com grandes pudores esse provincianismo. Formou-se em sociologia na Universidade de Columbia, viajou a Europa, parou em Oxford, vai dar breve um livrão sobre a formação da vida social brasileira... Pois timbra em ser provinciano, pernambucano, do Recife. Quando dirigiu um jornal lá, fez questão de lhe dar feitio e caráter bem provincianos. Nele colaborei com delícia durante uns dois anos. Foi nas páginas da A Provincia que peguei este jeito provinciano de conversar. No Rio lá se pode fazer isso? É só o tempo de passar, dar um palpite, uma bola, como agora se diz, nem se acredita em nada, salvo no primeiro boato. ${ }^{22}$

\footnotetext{
21 FRIEDRICH, Hugo. Estrutura da lírica moderna. São Paulo: Duas Cidades, 1978.

22 BANDEIRA, Manuel. Poesia completa e prosa. Rio de Janeiro: Nova Aguilar, 1974, p. 668. Crônica escrita para o Estado de Minas, Belo Horizonte, 12.03.1933.
} 
Seria talvez possível afirmar que Bandeira foi, dentre os escritores empenhados em compor a partir de uma experiência que se queria genuinamente brasileira, e nesse sentido provinciana, quem melhor universalizou sua expressão lírica pela vivência do particular. E, nesse contexto, é o poeta que permite, por sua justeza exemplar, a encenação espirituosa do "líder intelectual da província" Gilberto Freyre. Na leitura de correspondência, os choques de superfície não interferem no todo, ou melhor, positivamente o intensificam. Como num arranjo profundamente harmônico, temos duas personalidades exemplares que se combinam na contradição: de um lado, o homem simples e circunspecto; de outro, o homem ávido e espirituoso. Um encontro, pode-se dizer, genuinamente brasileiro e singularmente pernambucano, como os melhores personagens de Casa-grande \& senzala, testemunhando uma amizade que atravessa os tempos na "província do Brasil".

O processo de modernização no Brasil não pode ser analisado sem que se leve em conta a sua situação colonial. A tentativa de construir uma identidade cultural brasileira acaba por assumir um sentido mais problemático em um país em que o arcaico convive contraditoriamente com o moderno, em que uma enorme massa de excluídos convive com uma pequena elite voraz, em que as bases político-econômicas ainda não permitem uma modernização uniforme e inclusiva. Ser provinciano na primeira metade do século $\mathrm{xx}$, além de estar em uma linha de fuga com relação à capital federal e a outros poucos centros econômicos brasileiros como São Paulo, ainda significa construir um discurso de afirmação nacional diante da força modernizadora, tecnológica, racional e abstratizante que vem, de forma avassaladora, dos centros metropolitanos mundiais. Bandeira, na década de 1920, tornou-se um provinciano de primeira linha. A amizade epistolar com Gilberto Freyre parece ter sido decisiva para tal. Escreve o autor de Casa-grande \& senzala:

Nossa amizade começou por carta. Começou com a carta que um dia recebi dele; que li com uma alegria enorme e que devo ter guardada entre os meus papéis mais queridos. Era uma carta cheia de simpatia pelos artigos meio líricos que eu andava então escrevendo no Diário de Pernambuco, num português ainda mais perto que o de hoje, português de quem tinha saído daqui quase menino para voltar homem feito, depois de cinco anos maciços de língua inglesa. Artigos sobre coisas de Pernambuco, 
do Recife, do Norte. Sobre a paisagem, sobre os nomes da rua, sobre a cozinha tradicional do Norte do Brasil. ${ }^{23}$

A resposta de Freyre ao elogio encontrado na primeira carta de Manuel Bandeira é a encomenda de um poema para a edição comemorativa do centenário do Diário de Pernambuco. Depois de certa relutância, Bandeira envia "Evocação do Recife", publicado em destaque no Livro do Nordeste. ${ }^{24}$ A partir dessa aproximação evidente com a província, Bandeira, coincidência ou não, toma este como um tema dos mais recorrentes de sua poética.

A dignificação do cotidiano humilde de pessoas comuns vem junto com memórias da infância e com um sentimento particular da província, ou seja, da terra natal e das coisas brasileiras. ${ }^{25}$ Seguindo aqui a linha de Erich Auerbach, ${ }^{26}$ explorada por Davi Arrigucci Jr. em Humildade, paixão e morte, ${ }^{27}$ percebe-se que Bandeira cria um sublime particular, combinando o mais baixo, o realismo mais cru, com o mais elevado, uma revelação do mistério oculto a partir do cotidiano. Enquanto essa fusão é a mais perfeitamente acabada para o poeta, em Freyre as fissuras ficam evidentes. Do mesmo modo, este traz o cotidiano humilde, mas também combina um estilo orgulhoso, cultivado, retórico. Essa junçāo, como não poderia deixar de ser, é bastante problemática, quase esquizofrênica, e seus interstícios

23 FREYRE, Gilberto. Manuel Bandeira, recifense. In: Perfil de Euclydes e outros perfis. Rio de Janeiro: José Olympio, 1944, P. 176.

24 FREYRE, Gilberto e outros. Livro do Nordeste. Edição comemorativa do primeiro centenário do Diário de Pernambuco. Recife: Secretaria da Justiça, Arquivo Público Estadual, 1979 - edição fac-similar.

25 Na "advertência" às Crônicas da província do Brasil, escreve Manuel Bandeira: "A maioria destes artigos de jornal foram escritos às pressas para A Província do Recife, Diário Nacional de São Paulo e O Estado de Minas de Belo Horizonte. Eram crônicas de um provinciano para a província. Aliás este mesmo Rio de Janeiro de nós todos não guarda, até hoje, uma aima de província? O Brasil todo é ainda província. Deus o conserve assim por muitos anos!". (BANDEIRA, Manuel. Op. cit., 2006). Vale ainda dizer que Manuel Bandeira foi colaborador do jornal A Província quando este era dirigido por Gilberto Freyre. O sociólogo pernambucano, ao assumir a direçāo do jornal a pedido do então governador Estácio Coimbra, procurou desenvolver um trabalho diferenciado, seguindo uma linha editorial que o destacasse dos demais periódicos em circulaçāo.

26 AUERBACH, Erich. Mimesis. Sāo Paulo: Perspectiva, 1976.

27 ARRIGUCCI JR., Davi. Humildade, paixão e morte: a poesia de Manuel Bandeira. São Paulo: Companhia das Letras, 1991 
saltam à vista quando nos damos conta, por exemplo, da altivez pretensiosamente aristocrática com que fala da herança africana e indígena na vida brasileira. Ao contrário de Bandeira, que parece não crer em ações grandiosas e definitivas, Freyre, principalmente aquele mais político, encarna exemplarmente o destino do próprio país, cada vez mais consciente dos seus diversos matizes culturais e da necessidade de se propor ativamente um processo definitivo de inclusão e de superação do atraso econômico e social do país, mas ainda temeroso acerca de quais rumos tomar, ou talvez bastante confiante de que os contrários, por mais díspares que sejam, podem, de fato, conviver em harmonia.

Silvana Moreli Vicente é doutora em Teoria Literária e Literatura Comparada pela Universidade de São Paulo. Prepara a edição da correspondência Manuel Bandeira \& Gilberto Freyre. 